\title{
Farklı çözücü türlerinin ekstraksiyon reçinesinin verimi ve kimyasal özellikleri üzerine etkisi
}

\author{
Naile Angın a,* (iD, Murat Ertaşa (i)
}

\begin{abstract}
Özet: İğne yapraklı ağaçlardan farklı tekniklerle üretilen doğal çam reçinesi, oldukça kıymetli ve kadim bir silvikimyasal üründür. Başta kimya sanayi olmak üzere, kağıt, yol boyası, plastik sanayi, tıp ve kozmetikte sayısız kullanımı mevcuttur. Doğal çam reçinesinin üç kaynağı bulunmaktadır. Bunlar; 1) çam ağacı reçinesi 2) sülfat reçinesi 3) ekstrakt reçinesidir. Son yıllarda bütün dünyada sentetik reçine tüketimine getirilen yasal kısıtlamalar sektörü zorunlu olarak biyobozunur ürünlere yönlendirmektedir. Türkiye'de reçine üretimine uygun kızılçam ormanları olmasına rağmen, bugün ticari anlamda doğal ham reçine üretimi ve bu konu üzerine bilimsel çalışmalar istenilen düzeyde değildir. Bu çalışmanın amacı, farklı çözücü türlerinin çam kökü ekstraksiyon reçinesinin verimi ve kimyasal özellikleri üzerine etkisini incelemektir. Analizler sonucunda ekstraksiyon verimleri $\% 16$ ile $\% 22$ arasında bulunmuş olup en yüksek verim alkol-benzen çözücü sisteminde elde edilmiştir. Verime paralel şekilde, en yüksek asit ve sabunlaşma sayıları da alkol-benzen kullanılan örneklerde sırasıla 174,87 ve $180,33 \mathrm{mgKOH} / \mathrm{g}$ bulunmuştur. Milli kaynaklarımızın ve ekstraksiyon reçinesi üretimindeki mevcut potansiyelimizin değerlendirilmesi için doğal reçinenin verimini ve kalitesini etkileyen fiziksel ve kimyasal faktörler üzerine daha detaylı ve etkin çalışmalar yürütülmesi gerekmektedir.

Anahtar kelimeler: Ekstraksiyon reçinesi, Kolofan, Asit sayısı, Sabunlaşma sayısı, Odun dışı orman ürünleri
\end{abstract}

\section{Effect of solvent types on the yield and chemical properties of crude wood resin}

\begin{abstract}
Natural pine resin, produced from coniferous species with different techniques is a very valuable and ancient biochemical product. It has wide uses in the chemical industry, paper, road paint, plastic, medicine and cosmetic industries. In recent years, legal restrictions all over the world on consumption of synthetic resin lead the industry to biodegradable products. Although there are suitable forests for natural resin production in Turkey, commercial manufacturing and scientific studies on this subject are not at the desired level today. The aim of this study is to examine the effect of different solvent types on the yield and chemical properties of crude wood resin. As a result of the analysis, extraction yields were found between $16 \%$ and $22 \%$, and the highest yield was obtained in the ethanol-benzene solvent system. Collaterally to the yield, the highest acid and saponification numbers were found in alcohol-benzene extracts as 174,87 and $180,33 \mathrm{mg} \mathrm{KOH} / \mathrm{g}$, respectively. In order to evaluate our national resources and our current potential in crude wood rosin production, more detailed and effective studies should be carried out on the physical and chemical factors that affect the yield and quality of crude wood rosin .
\end{abstract}

Keywords: Crude wood resin, Colophony, Acid number, Saponification number, Non-wood forest products

\section{Giriş}

Değişen çevre ve yaşam şartları ile birlikte, orman kaynaklarından odun eldesi yanında katma değerli odun dışı orman ürünlerinin üretilmesine de dair ilgi ve talep gün geçtikçe artmaktadır (Büyükgebiz vd., 2008). Son yıllarda ülkemizde bu talebin karşılanmasına yönelik atılan bilinçli adımlar hem milli servetlerin etkin kullanımına hem de kırsal kalkınmaya fayda sağlanmaktadır (Kurt vd., 2016).

Doğal reçine, kadim ve kıymetli bir odun dışı orman ürünüdür. Reçinenin tarihinin milattan önceki zamanlara kadar dayandığı ve kutsal kitaplarda çam katranı, odun zifti vb isimlerle adlandırıldığ 1 bilinmektedir. Hz. Nuh'un ahşaptan yaptığı gemisini korumak maksadıyla suya değen kısımların içini ve dışını reçine (zift) ile kapladığı rivayet edilmektedir (Zinkel, 1975). Benzer şekilde, yabancı literatürde reçine ürünleri "Naval Stores" adıyla geçmektedir. Naval, ingilizcede denizcilikle kullanılan kimyasallara verilen genel bir isimdir. Gemi endüstrisinde kullanılan reçineli odun katranı halat ve yelkenlerin çürümesini önlemiş ve teknenin kenar ve diplerinden olabilecek sızıntıları önlemiştir (Outland, 1996).

Reçine çoğunlukla iğne yapraklı ağaç türleri tarafindan salgılanmaktadır ve ekseriyetle gövde ve köklerde üretilmektedir (Erdin ve Bozkurt, 2013). Geçmiş yıllar boyunca ağaçlardan ekstrakte edilebilen tüm yapışkan ve akıcı kıvamlı maddeleri reçine olarak karakterize etme eğilimi olmuştur ve genellikle sakızlar, yağlar, vakslar ve balzamlar ile karıştırılmaktadır. Ancak reçinenin salgılanışı ve kimyasal yapısı bu bileşiklerden daha farklıdır (Langenheim, 1990). Reçine, salgılandıktan sonra bir daha ağaç bünyesi tarafından kullanılmayan, ağacın öz savunmasında etkili bir kimyasal bileşimdir (Kolosova ve Bohlmann, 2012). Günümüzde bilimsel atılımlarla ilişkili olarak, reçinelerin bitkilerdeki fonksiyonları ile ilgili anatomik ve ekolojik kavramlarda ilerlemeler olmuştur.

\footnotetext{
$\llbracket$ a Orman Endüstri Mühendisliği Bölümü, Orman Fakültesi, Bursa Teknik Üniversitesi, 16310, Bursa, Türkiye

@ * Corresponding author (İletişim yazarı): naile.angin@ btu.edu.tr

$\checkmark \quad$ Received (Geliş tarihi): 01.07.2021, Accepted (Kabul tarihi): 22.11.2021
}

Citation (Atıf): Angın, N., Ertaş, M., 2021. Farklı çözücü türlerinin ekstraksiyon reçinesinin verimi ve kimyasal özellikleri üzerine etkisi. Turkish Journal of Forestry, 22(4): 439-443. DOI: $10.18182 /$ tjf.960674 
Örneğin Lopez-Goldar vd. (2020), reçinenin kimyasal içeriğinin yalnızca coğrafi ve anatomik etmenlere bağlı olmadığını, uyarıcı biyolojik tehlikenin cinsine göre reçine asitleri bileşiminde farklılık görüleceğini öne sürmüşler ve ağaca arız olan böcek türüne göre reçinenin kimyasal kompozisyonunda farklılıklar olduğunu tespit etmişlerdir.

Doğal reçine, günümüzde akma reçine, sülfat reçinesi ve ekstraksiyon reçinesi olmak üzere üç farklı teknik ile üretilmektedir (Şekil 1). Her üç teknikte de temel reçine kaynağ1 ağaçtır ancak üretim tekniği ve elde edilen ürünün kimyasal özelliklerinin birbirinden farklı olduğu bilinmektedir (Joye vd., 1973).

En eski ve en bilinen yöntem akma reçine yöntemidir. Bu yöntemde dikili, canlı çam ağacının gövdesine farklı yöntemlerle pencereler açılarak; salgılanan reçine oldukça emek gerektiren işlemlerle toplanmaktadır (Deniz, 2002; Deniz, 2018). İkinci yöntem olan sülfat reçinesi; reçineli çam yongalarından sülfat yöntemiyle (kraft yöntemi) kâğıt hamuru üretiminde yan ürün olarak elde edilmektedir. Yongaların pişirilmesi esnasında açı̆̆a çıkan gazların distilasyonuyla sülfat terebentini, pişirmeden sonra oluşan alkali siyah çözeltiden de ham tall oil ve yağ asitleri elde edilmektedir (Aro ve Fatehi, 2017). Üçüncü yöntem olan ekstraksiyon reçinesi; kesimden sonra uzun süre toprakta bekleyerek çıralanmış reçineli çam köklerinin yongalanarak, tesislerde uygun çözücü ekstraksiyonuyla elde edilmektedir. Ekstraksiyon sonucunda, odun ekstraksiyon terebentini, odun ekstraksiyon kolofanı, dipenten ve doğal pineoil elde edilmektedir (Humphrey, 1943).

Ekstraksiyon reçinesi, diğer reçine türlerine göre hem hammadde tedariği hem de üretim tekniği olarak oldukça farklıdır ve endüstriyel üretime daha uygun bir yöntemdir. Ekstraksiyon metodunda önemli olan kökteki reçinenin yapısını ve kalitesini bozmadan; en ucuz ve uygun çözücü kullanarak reçineyi ağaçtan izole etmektir (Linlin vd., 2005). Bu teknikte kullanılan çam kökleri kesim yapılmış, yanmış veya bozuk orman sahalarının toprak altında kalmış atıl ürünleridir. Bu köklerin işlenmesiyle doğaya ve ekonomiye hiç de azımsanmayacak katkılar sağlanır. Toprak altında kalan, terkedilmiş çam kökleri ekonomiye kazandırılır. Dahası, kök çıkarma işlemi, bu işte çalışacak orman köylüsüne büyük ekonomik katkı sağlar ve orman köylüsüne yeni iş sahası açar. Ülkemizde çam köklerinden ekstraksiyon yöntemi ile reçine üretimine bakıldığında, geçmiş yıllarda özellikle Balıkesir bölgesinde reçine üretilmesine rağmen, uluslararas1 pazarlarda belirlenen fiyatlarla rekabet edilemediği için, bu fabrikaların zamanla kapandığı görülmektedir (Güle, 2019). Günümüzde, BalıkesirEdremit'te ekstraksiyon reçinesi üreten bir fabrika çalışmaktadır.

Doğal reçinenin kimyasal yapısı incelendiğinde; benzer temel yapıya sahip reçine asitlerinden ve terpenlerden oluşan doğal bir karışım olduğu görülmüştür (Wilbon vd., 2013). Literatürde, katı ya da yarı akışkan, berraklaşması güç, suda çözünmeyen, organik çözücülerde çözünen, isitılınca yumuşayan ve eriyen şekillenmemiş maddeler olarak tanımlanmıştır (Güner, 2015; Öz vd., 2012).

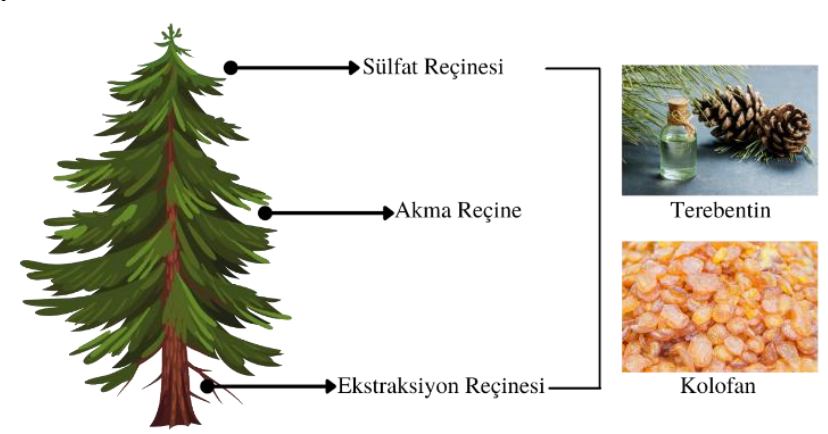

Şekil 1. Doğal reçine üretim teknikleri ve reçinenin bileşenleri (CanvaPro ile düzenlenmiştir.)

Doğal reçine temel olarak kolofan ve terebentin olmak üzere iki kısımdan oluşur. $\mathrm{Bu}$ bileşenleri birbirinden ayırabilmek için distilasyona tabi tutmak gerekmektedir (Beglinger, 1958). Uçucu kısım terebentin adını alır ve yapısında terpenler bulundurur. Distilasyon sonrasinda geriye kalan ve reçine asitleri içeren katı kısım ise kolofan olarak adlandırılmaktadır (Huş, 1959; Deniz vd., 2019). Reçinenin \%60-70 oranında kolofan içerdiği bildirilse de reçine bileşenleri üretim tekniğine ve distilasyon prosesine bağlı olarak değişken bir kimyasal bileşim oranlarına sahiptir ve ihtiva ettiği reçine asitleri ve miktarları da farklıdır (Angın, 2020). Reçinenin kimyasal kompozisyonun yanında asit ve sabunlaşma sayısı gibi önemli kimyasal indikatörler de bundan etkilenmektedir (Panda, 2013). Öte yandan, reçinenin fiziksel ve kimyasal özellikleri, reçinenin kalite sınıfını belirlemektedir ve kullanım yeri ve fiyatlandırılması üzerine doğrudan etki ederek piyasadaki rekabet unsurlarını oluşturmaktadır. Distilasyon sonunda elde edilen, hem terebentin hem de kolofan endüstriyel anlamda çok kıymetli olup, eczacılık, kağıtçılık, boya ve mürekkep sanayi, otomotiv vb. olmak üzere birçok farklı alanda ara ve temel kimyasal madde olarak kullanılmaktadırlar (Karlberg ve Hagvall, 2020).

$\mathrm{Bu}$ çalışmada, farklı çözücü türlerinin çam kökü ekstraksiyon reçinesinin verimi ve asit ve sabunlaşma sayısını belirlenerek kimyasal özellikleri üzerindeki etkisi incelenmiştir.

\section{Materyal ve yöntem}

\subsection{Materyal}

Hammadde olarak yongalanmış kızılçam (Pinus brutia Ten.) kökü kullanılmıştır. Yongalanmış ve kullanıma hazır çam kökü örnekleri İVA Reçine Biyokütle A.Ş.'den bedelsiz olarak temin edilmiştir. Kökler herhangi bir ön işleme ve ayırmaya tabi tutulmadan ekstraksiyona tabi tutulmuştur. Ekstraksiyon işleminde çözücü olarak; etanol (\%99,9, IsoLab), n-hekzan (\%99, VWR Chemicals), dietil eter (Sigma-Aldrich) ve yüzde 30:70 oranında etanol-benzen (Sigma-Aldrich) kullanılmıştır.

\subsection{Yöntem}

\subsubsection{Ekstraksiyon}

Yongalanmış ve hava kurusu hale getirilmiş çam kökleri TS 4424 nolu standart uyarınca her bir çözücü ile 6 saat süreyle soxhlet cihazında (Behr, Germany) üç tekrarlı olarak ekstrakte edilmiştir. Ekstraksiyon sonunda, balonda biriken 
çözelti içerisinde kalan çözücü bir vakumlu evaporatör (Heidolph, Germany) yardımı ile geri kazanılmış ve elde edilen ekstrakt miktarı tartılmıştır. Reçine veriminin hesabı tam kuru kök ağırlığı üzerinden hesaplanmıştır (Eşitlik 1).

$$
R M=\frac{\mathrm{Ex}}{M_{0}} \times 100
$$

Bu eşitlikte;

$\mathrm{RM}=$ Reçine verimi (\%),

Ex = Balondaki ekstraktın ağırlığı $(\mathrm{g})$,

$\mathrm{M}_{0}=$ Tam kuru kök ağırlığ 1 (g)'nı ifade etmektedir.

\subsubsection{Distilasyon}

Asit ve sabunlaşma sayısı kolofan üzerinden hesaplanmaktadır, bu nedenle reçinenin terebentin ve kolofana ayrılması gerekmektedir. Bu işlem için sıcaklık ayarlı ve manyetik karıştırıcı özellikli mantolu 1sıtıcı (Elektromag, India) kullanılmıştır. Yoğuşturucu olarak; su soğutmalı köprü tipi bir geri soğutucu kullanılmıştır. Distilasyona $30{ }^{\circ} \mathrm{C}$ 'den başlanmış ve her 10 dakikada bir 10 ${ }^{\circ} \mathrm{C}$ arttırılarak $240{ }^{\circ} \mathrm{C}$ 'ye kadar 1 sıtılmış ve distilasyon sonunda balonda kalan kolofan numune kaplarına alınıp soğumaya bırakılmıştır.

\subsubsection{Asit sayıs tayini}

Asit sayısı tayini TS 4862 nolu standart uyarınca gerçekleştirilmiştir. 4 gram kolofan örneği $100 \mathrm{~mL}$ etanol (IsoLab, \%99.9) içerisinde çözüldükten sonra karışımın üzerine, indikatör olarak \%1'lik (w/v) olarak hazırlanmış, fenolftalein (Sigma Aldrich) çözeltisinden $1 \mathrm{~mL}$ damlatılmıştır. Hazırlanan karışım, etil alkol ile hazırlanmış $0,5 \mathrm{~N}$ potasyum hidroksit $(\mathrm{KOH})$ çözeltisi kullanılarak titre edilmiştir. Dönüm noktasında harcanan $\mathrm{KOH}$ çözeltisi miktarı kaydedilmiş ve Eşitlik 2 yardımıyla asit sayısı hesaplanmıştır.

$$
\begin{aligned}
& \text { Asit Sayısı }=\frac{A \times N \times 56,1}{B} \\
& \text { Bu eşitlikte; } \\
& \text { A= Harcanan KOH çözeltisinin hacmi (ml) } \\
& \text { N= KOH çözeltisinin normalitesi } \\
& B=\text { Başlangıçta kullanılan kolofanın ağırlığ }(\mathrm{g}) \\
& \text { 56,1=KOH molekül ağırlığı'nı ifade etmektedir. }
\end{aligned}
$$

\subsubsection{Sabunlaşma sayısı tayini}

$\mathrm{Bu}$ analiz TS 4863 nolu standart uyarınca gerçekleştirilmiştir. 4 gram kolofan örneği $50 \mathrm{~mL}$ etanol içerisinde çözüldükten sonra karışımın üzerine $50 \mathrm{~mL} \mathrm{KOH}$ eklenmiş ve sabunlaşma reaksiyonu için 1 saat süreyle geri soğutucu altında kaynatılmıştır. Aynı işlemler şahit deneme için de tekrarlandıktan sonra çözeltiler oda sıcaklığına soğutulmuş ve $0,5 \mathrm{~N}$ sülfürik asit $\left(\mathrm{H}_{2} \mathrm{SO}_{4}\right)$ çözeltisi ile titre edilmiştir. Dönüm noktasında harcanan miktarlar kaydedilmiş ve Eşitlik 3 yardımıyla sabunlaşma sayısı hesaplanmıştır.

$$
\text { Sabunlaşma Sayısı }=\frac{(B-A) \times N \times 56,1}{C}
$$

Bu eşitlikte; (ml)

$\mathrm{A}=$ Deney örneği için harcanan $\mathrm{H}_{2} \mathrm{SO}_{4}$ çözeltisinin hacmi (ml)

$\mathrm{B}=$ Şahit örnek için harcanan $\mathrm{H}_{2} \mathrm{SO}_{4}$ çözeltisinin hacmi

$\mathrm{C}=$ Başlangıçta kullanılan kolofanın ağırlığı $(\mathrm{g})$

$\mathrm{N}=\mathrm{H}_{2} \mathrm{SO}_{4}$ çözeltisinin normalitesi

$56,1=\mathrm{KOH}$ molekül ağırlı̆̆ı'nı ifade etmektedir.

\section{Bulgular ve tartışma}

\subsection{Reçine verimi}

Farklı çözücülerle gerçekleştirilen ekstraksiyon sonucunda hesaplanan reçine verimleri Çizelge 1 ve Şekil 2 'de gösterilmiştir.

Sonuçlar incelendiğinde, en yüksek reçine verimi sirasiyla $\% 22,44$ ve $\% 20,86$ olmak üzere alkol-benzen ve etanol kullanılan örneklerde elde edilmiştir. Dietil eter ve nhekzan kullanılan örneklerden görece daha az verim elde edilmiştir. Bu durum, çözücü türlerinin farklı polariteye sahip olmasına atfedilebilir. Bilindiği üzere n-hekzan ve dietil eter apolar özellikteyken, etanol bunlara kıyasla daha polar bir çözücüdür (Efthymiopoulos vd., 2018). İdeal bir ekstraksiyon işleminde mümkün olduğunca çok hedef bileşiğin çözücü fazına geçmesi beklenmektedir ve dolayısıyla "benzer benzeri çözer" presibinden yola çıkılarak uygun polaritede çözücü ile ekstrakte edilir (Handa, 2008; Swami vd., 2008). $\mathrm{Bu}$ bağlamda, polar organik çözücüler (etanol, metanol, aseton vb.) genellikle biyo-bazlı örneklerin ekstraksiyonunda tercih edilmektedir. Bunun nedeni alkollü çözücülerin hücre duvarını daha iyi geçmeleri, çok sayıda orta ve düşük polariteye sahip bileşikleri daha iyi bir şekilde ekstre etmelerine dayanmaktadır (Abubakar ve Haque, 2020). Bu bilgiler ışı̆̆ında, etanol ve alkol-benzen kullanılan örneklerin daha yüksek reçine verimine sahip olmasının literatür ile uyumlu olduğu görülmüştür.

Çizelge 1. Çözücü türlerinin reçine verimine etkisi

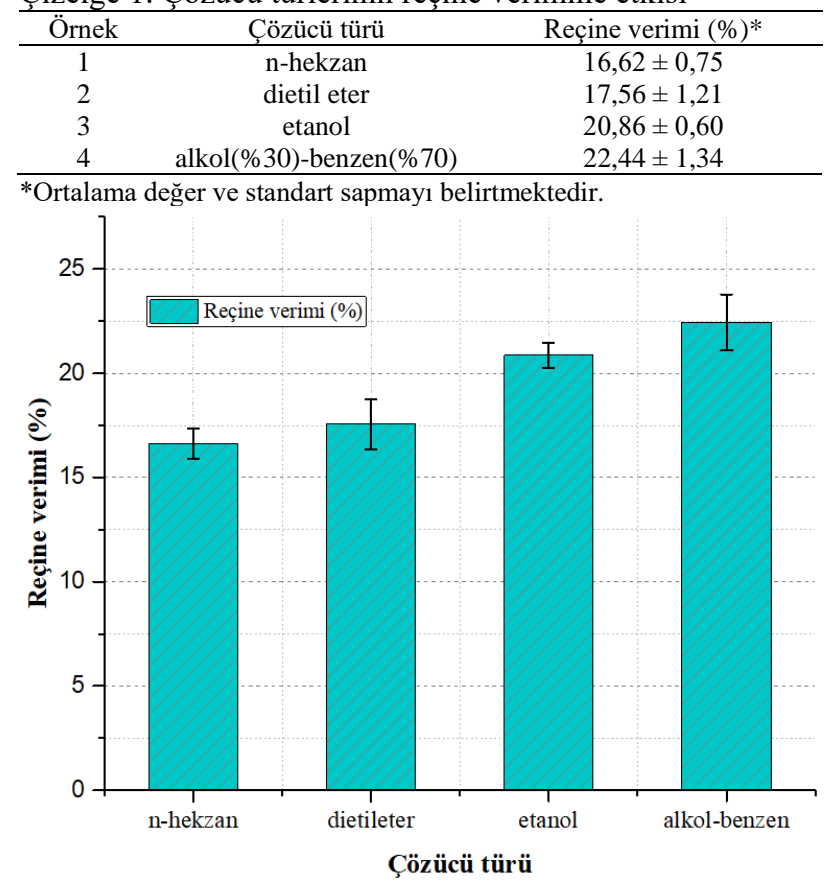

Şekil 2: Çözücü türlerinin reçine verimine etkisi 
Her ne kadar alkol-benzen kullanımında ekstraksiyon verimi daha yüksek olsa da; çözücü karışımlarında bir çözücü diğerinden daha önce kaynayabilmekte bu da ekstraksiyon çözücüsünün karışım oranlarının değişmesine neden olabilmektedir (Swami vd., 2008). Bu durum bilhassa endüstriyel uygulamalarda prosesin kontrol edilmesini zorlaştırabilir. Öte yandan, günümüzde verimliliğin yanı sıra çevresel etki ve işçi sağlığı faktörleri de çözücü seçiminde oldukça önemli bir rol oynamaktadır (Poliakoff ve Licence, 2007). Benzen'in insan sağlığını tehdit eden zararları nedeniyle endüstriyel kullanımında sinırlamalar olduğu bilinmektedir (McQuaid, 1991).

Çözücü seçiminde göz önünde bulundurulması gereken bir diğer faktör ise enerji sarfiyatıdır (Woerfel, 1995). Seçilen çözücünün yüksek kaynama noktasına sahip olması 1sıtma için kullanılan enerji sarfiyatını arttırırken, diğer yandan düşük kaynama noktalı uçucu çözücülerin de fabrika sahalarında depolanması ve taşınması için ilave işlemlere ve enerjiye ihtiyaç duyulmaktadır. Böyle durumlarda ekstraksiyon verimi daha düşük olmasına rağmen, sağladığı enerji tasarrufu ve geri kazanım kolaylığı nedeni ile n-hekzan gibi optimum $65-69^{\circ} \mathrm{C}$ arasında kaynayan çözücüler endüstriyel uygulamalarda tercih edilmektedir. Örneğin, Edremit'te bulunan kök reçinesi üretim tesisinde ekstraksiyonun hekzan kullanılarak gerçekleştirildiği bilinmektir.

\subsection{Asit ve sabunlaşma sayısı}

Kolofan örneklerinin asit ve sabunlaşma sayıları Çizelge 2'de verilmiştir. Asit sayısı, 1 gram kolofanda bulunan serbest asidi nötrleştirmek amacıyla kullanılan potasyum hidroksitin $(\mathrm{KOH})$ miligram cinsinden miktarı olarak tanımlanmaktadır (TS 4862). En yüksek asit sayısı alkolbenzen ekstraksiyonundan elde edilen kolofan örneğinde, $174,87 \pm 3,22 \mathrm{mg} \mathrm{KOH} / \mathrm{g}$ olarak bulunmuştur. Asit sayısı, kolofanın içerdiği serbest reçine asitleri miktarıyla doğrudan ilgilidir. Örnek içerisinde ne kadar fazla serbest reçine asiti varsa nötrleştirilmesi için o kadar fazla $\mathrm{KOH}$ çözeltisi harcanacaktır ve asit sayısının da bu nispette daha yüksek çıkması beklenmektedir (Baldwin vd., 1958). Bu bağlamda alkol-benzen kullanılan örnekte, apolar-polar çözücü sisteminin olumlu ektisiyle daha fazla asidik yapıda bileşenin ekstrakte edildiği ve bunun asit sayısına yansıdığ düşünülmektedir. Öte yandan bu düşünceyi destekler şekilde, yalnızca polar veya apolar çözücü kullanılan örneklerin asit sayısında kayda değer bir düşüş olduğu gözlemlenmiştir.

Çizelge 2. Çözücü türlerinin asit ve sabunlaşma sayısına etkisi

\begin{tabular}{cccc}
\hline Örnek & Çözücü türü & $\begin{array}{c}\text { Asit say1s1* } \\
(\mathrm{mg} \mathrm{KOH} / \mathrm{g})\end{array}$ & $\begin{array}{c}\text { Sabunlaşma say1s1* } \\
(\mathrm{mg} \mathrm{KOH} / \mathrm{g})\end{array}$ \\
\hline 1 & n-hekzan & $162,26 \pm 1,35$ & $174,88 \pm 2,73$ \\
2 & dietil eter & $163,47 \pm 1,78$ & $173,31 \pm 4,06$ \\
3 & etanol & $169,11 \pm 2,65$ & $177,05 \pm 2,84$ \\
4 & alkol(\%30)-benzen(\%70) & $174,87 \pm 3,22$ & $180,33 \pm 2,71$ \\
\hline *Ortalama dĕgr ve standart sapmay1 belirtmektedir.
\end{tabular}

*Ortalama değer ve standart sapmayı belirtmektedir.
Sabunlaşma sayısı; 1 gram kolofanın nötrleştirilmesinin akabinde sabunlaştırılmasında kullanılan potasyum hidroksitin $(\mathrm{KOH})$ miligram miktarı olarak tanımlanmaktadır (TS 4863). Asit sayısında da olduğu gibi; sabunlaşma sayısının belirlenmesinde de reçine içerisindeki abietik asit,pimarik asit, palustrik asit vb. serbest asitlerin konsantrasyonu önemlidir. Nötrleşen reçine asidi miktarıyla doğru orantılı olarak sabunlaşma olması beklenmektedir. En yüksek sabunlaşma sayısı alkol-benzen ekstraksiyonundan elde edilen kolofan örneğinde, 180,33 $\pm 2,71 \mathrm{mg} \mathrm{KOH} / \mathrm{g}$ olarak bulunmuştur. Bu sonucu destekler nitelikte, daha önceki çalışmalar daha polar çözücü kullanılarak elde edilen yağların, doymuş yağ asitlerinin ve vaksların daha yüksek sabunlaşma sayısı verdiğini göstermiştir (Efthymiopoulos vd., 2018; Smith, 1937). Bulunan değerler diğer reçine türleri ile kıyaslandığında, SEKA kâğıt fabrikasından elde edilen tall oil reçinesinin sabunlaşma sayısının $162 \mathrm{mg} \mathrm{KOH} / \mathrm{g}$ ve akma reçine üzerine yapılan bir çalışmada ise sabunlaşma sayısının yaklaşık $170 \mathrm{mg} \mathrm{KOH/g}$ civarında bulunduğu bildirilmiştir (Keskin vd., 2007; Sukarno, 2018, Deniz, 1987; Coppen vd., 1995). Endüstriyel kullanımda sabunlaşma sayısının $150 \mathrm{mg} \mathrm{KOH/g} \mathrm{üzerinde} \mathrm{olması} \mathrm{istenir} \mathrm{ve} \mathrm{ne} \mathrm{kadar}$ yüksek olursa türevlendirme reaksiyonlarında kullanıma o kadar elverişli hale gelir. Bu açıdan değerlendirildiğinde ekstraksiyon reçinesinin diğerlerine göre endüstriyel anlamda daha avantajlı olduğu düşünülmektedir.

\section{Sonuç}

$\mathrm{Bu}$ çalışmada, farklı çözücü türlerinin çam kökü ekstraksiyon reçinesinin verimine ve kimyasal özellikleri üzerine etkisi incelenmiştir. Sonuçlar, polar çözücüyle gerçekleştirilen eksraksiyon veriminin daha yüksek olduğunu ve apolar çözücü kullanılarak elde edilen örneklere göre yaklaşık \%5 oranında arttı̆̆ını göstermiştir. Diğer taraftan, ekstraksiyon verimine paralel olarak asit ve sabunlaşma sayılarında da artışlar olmuştur. Özellikle alkol-benzen çözücü sisteminde ortalama $10 \mathrm{mg} \mathrm{KOH} / \mathrm{gr}$ civarında kayda değer bir artış gözlemlenmiştir. Günümüzde, küresel reçine piyasasındaki rekabeti reçinenin kalite sınıfı belirlemektedir. Asit ve sabunlaşma sayısının yüksek olması endüstriyel açıdan arzu edilen bir durumdur ve kalite sınıfına doğrudan etki eden önemli parametrelerdir. Bu nedenle, ham reçine üretilirken ve fraksiyonlanırken tüm proses adımlarının bu parametreler üzerine olan etkisinin incelenmesi önerilmektedir.

\section{Kaynaklar}

Abubakar, A.R., Haque, M., 2020. Preparation of medicinal plants: Basic extraction and fractionation procedures for experimental purposes. Journal of Pharmacy \& Bioallied Sciences, 12(1): 110.

Angın, N., 2020. Çam kökü ekstraksiyon reçinesinin distilasyonu ve kimyasal karakterizasyonu. Yüksek Lisans Tezi, Bursa Teknik Üniversitesi Fen Bilimleri Enstitüsü, Bursa.

Aro, T., Fatehi, P., 2017. Tall oil production from black liquor: Challenges and opportunities. Separation and Purification Technology, 175:469-480.

Baldwin, D., Loeblich, V., Lawrence, R., 1958. Acidic composition of oleoresins and rosins. Industrial Engineering Chemistry Chemical and Engineering Data Series, 3(2): 342-346.

Beglinger, E., 1958. Distillation of resinous wood (Revised Report 496). Madison (WI): Forest Products Laboratory, United States Department of Agriculture, Forest Service. 
Büyükgebiz, T., Fakir, H., Negiz, M., 2008. Sütçüler (Isparta) Yöresinde doğal odun dışı bitkisel orman ürünleri ve geleneksel kullanımları. Türkiye Ormancılık Dergisi, 9(1): 109-120.

Coppen, J.J. W., Hone, G.A., 1995. Gum Naval Stores: Turpentine And Rosin From Pine Resin. FAO, Italy.

Deniz, İ., 2002. Dikili ağaçlarda reçinenin biyosentezi ve reçine üretimi. Gazi Üniversitesi Kastamonu Eğitim Dergisi, 10(2): 375-386.

Deniz, İ., 2018. Odun Dıș Orman Ürünleri Endüstrisi. KTÜ, Orman Fakültesi, Orman Endüstri Mühendisliği Bölümü, Ders Notu, 256 s., Trabzon.

Deniz İ., Pekgözlü K.A., Dönmez İ.E., Karaoğul E., Yılmaz B., Ceylan E., Aydın, İ., 2019. Ülkemizde Üretilen Kolofanların Kimyasal Özellikleri, Kolofan ve Türevleri Çalıştayı, 2 Mayıs, İstanbul, s. 16.

Deniz, İ., 1987. Kızılçam (Pinus brutia Ten.) reçinesinin kimyasal özellikleri. Yüksek Lisans Tezi, Karadeniz Teknik Üniversitesi, Trabzon.

Efthymiopoulos, I., Hellier, P., Ladommatos, N., Russo-Profili, A., Eveleigh, A., Aliev, A., Kay, A., Mills-Lamptey, B., 2018. Influence of solvent selection and extraction temperature on yield and composition of lipids extracted from spent coffee grounds. Industrial Crops and Products, 119, 49-56.

Erdin, N., Bozkurt, Y., 2013. Odun Anatomisi. İstanbul Üniversitesi, Orman Fakültesi Yayınları. İstanbul.

Güle, M.E., 2019. Vazgeçilmez Ürün Kolofan. 1. Kolofan ve Türevleri Çalıştayı Bildirileri. 2 Mayıs, İstanbul, s. 49.

Güner, E., 2015. Toros Göknarı (Abies Cilicica) reçinesinin kimyasal analizi. Yüksek Lisans Tezi, Bartın Üniversitesi, Fen Bilimleri Enstitüsü, Bartın.

Handa, S.S., 2008. Extraction Technologies for Medicinal and Aromatic Plants, International Centre For Science And High Technology, Italy.

Humphrey, I.W., 1943. Solvent refining of wood rosin. Industrial \& Engineering Chemistry, 35(10): 1062-1067.

Huş, S., 1959. Kolofan ve terebantin yağından elde edilen yeni türevler ve bunların endüstrideki önemi. İstanbul Orman Fakültesi Dergisi, 9(1): 80-94.

Joye Jr, N.M., Proveaux, A.T., Lawrence, R.V., 1973. Composition of neutral oils from rosin. Journal of the American Oil Chemists' Society, 50(4): 104-107.

Karlberg, A.T., Hagvall, L., 2020. Colophony: Rosin in unmodified and modified form. Kanerva's Occupational Dermatology, 41(1): 607-624.

Keskin, A., Gürü, M., Altıparmak, D., 2007. Biodiesel production from tall oil with synthesized Mn and Ni based additives: Effects of the additives on fuel consumption and emissions. Fuel, 86(78): $1139-1143$.

Kolosova, N., Bohlmann, J., 2012. Conifer defense against insects and fungal pathogens: In Growth and defence in plants. Springer. New York.
Kurt, R., Karayılmazlar, S., İmren, E., Cabuk, Y., 2016. Türkiye ormancılık sektöründe odun dışı orman ürünleri: İhracat analizi. Bartın Orman Fakültesi Dergisi, 18(2): 158-167.

Langenheim, J.H., 1990. Plant resins. American Scientist, 78(1): 1624.

Linlin, W., Xiaopeng, C., Youyan, L., Yuanjiao, Z., Zhangfa, T., 2005. Isolation and application of rosin acids. Chemical Industry and Engineering Progress, 24(11): 1301.

López-Goldar, X., Lundborg, L., Borg-Karlson, A. K., Zas, R., Sampedro, L., 2020. Resin acids as inducible chemical defences of pine seedlings against chewing insects. PloS One, 15(5):1651.

McQuaid, J.L., 1991. Risk Assessment of Hazardous Air Pollutants Under the EPA's Final Benzene Rules and the Clean Air Act Amendments of 1990, 70: 427.

Outland, R.B., 1996. Slavery, work, and the geography of the North Carolina naval stores industry, 1835-1860. The Journal of Southern History, 62(1): 27-56.

Öz, M., Deniz, İ., Yaşar, M., Komut, O., Fidan, M.S., 2012. Kızılçam (Pinus brutia Ten.)'da reçine kelebeği (Dioryctria sylvestrella Ratz.) ve gövde reçinesinin uçucu yağ miktarları. KSÜ Doğa Bilimleri Dergisi, Özel Say1: 89-95

Panda, H., 2013. Handbook on tall oil rosin production, processing and utilization. Asia Pacific Business Press Inc. India.

Poliakoff, M., Licence, P., 2007. Green chemistry. Nature, 450(7171): 810-812.

Smith, W.C., 1937. Influence of solvent on the saponification number of rosin. Industrial \& Engineering Chemistry Analytical Edition, 9(10): 469-471.

Sukarno, A., 2018. Physical properties of turpentine and gum rosin pinus merkusii jungh et de vriese tapped oleoresin by borehole method. The Journal of Experimental Life Science, 8(1): 43-46.

Swami, H.S., Singh, K.S.P., Gennaro, L., Dutt, R.D., 2008. Extraction technologies for medicinal and aromatic plants. Trieste: United Nations Industrial Development Organization and the International Centre for Science and High Technology, 200-266.

TS 4862, 1986. Çam Reçinesi - Kolofanda Asit Sayısının Tayini. TSE, Ankara

TS 4863, 1986. Çam Reçinesi - Kolofanda Sabunlaşma Sayısının Tayini. TSE, Ankara.

Wilbon, P.A., Chu, F., Tang, C., 2013. Progress in renewable polymers from natural terpenes, terpenoids, and rosin. Macromolecular Rapid Communications, 34(1): 8-37.

Woerfel, J. B., 1995. Extraction In Practical handbook of soybean processing and utilization. AOCS Press. United States of America.

Zinkel, D. F., 1975. Naval stores: silvichemicals from pine. Applied Polymer Symposium, 28: 309-327. 